\title{
THE ANALGESIC EFFECT OF PREGABALIN, A COMPARATIVE STUDY WITH MORPHINE
}

\author{
Hassan A.Shabayek, Aly A.Mustafa, Nadia Esmat A.khorshid, and Hosam EL-Den A.mohammed \\ Clinical Pharmacology Department, Faculty of Medicine, Zagazig University
}

\begin{abstract}
Objectives: this study was designed to assess and compare the effects of pregabalin and morphine on acute thermal pain and on nerve injury associated pain (chronic neuropathic pain).

Methods: 72 male albino rats were divided into two major groups: group I (acute pain group) 30 rats divided into 5 equal subgroups (1)control, (2) pregabalin $30 \mathrm{mg} / \mathrm{kg}$, (3)morphine $0.5 \mathrm{mg} / \mathrm{kg}$, (4) pregabalin $60 \mathrm{mg} / \mathrm{kg}$, (5)morphine $1 \mathrm{mg} / \mathrm{kg}$, and group II(chronic pain group) 42 rats were divided into 7 equal subgroups (1)sham operated, (2)control normal, (3) control postoperative, (4) pregabalin 30mg/kg, (5) morphine $0.5 \mathrm{mg} / \mathrm{kg}$, (6) pregabalin $60 \mathrm{mg} / \mathrm{kg}$, (7) morphine $1 \mathrm{mg} / \mathrm{kg}$. For acute pain the reaction times, which indicate the tolerability of the animals to acute thermal pain, was measured using analgesia meter. However chronic neuropathic pain was induced in experimental animals by unilateral ligation of the sciatic nerve in the thigh.

Results: The result of the present study revealed that neither 30 nor $60 \mathrm{mg} / \mathrm{kg}$ pregabalin produced any significant effects on the tolerability of rats to acute thermal pain. On the other hand, pregabalin (30 and 60 $\mathrm{mg} / \mathrm{kg}$ ) markedly reversed allodynia and hyperalgesia in rats subjected to sciatic nerve ligation. The effect of pregabalin $30 \mathrm{mg} / \mathrm{kg}$ was noticed after 60 minutes and persist for 90 minutes but the higher dose $(60 \mathrm{mg} / \mathrm{kg})$ produced analgesic effect all over the experiment. On the other hand morphine 0.5 and $1 \mathrm{mg} / \mathrm{kg}$ significantly increased the tolerability of normal and sciatic nerve ligated rats to thermal nociception. The analgesic effect of morphine was more significant than that of pregabalin all over the experiments.

Conclusion: in contradiction to morphine, pregabalin was not effective for treatment of acute pain. Both pregabalin and morphine produced significant analgesic effect in neuropathic pain. The effect of morphine was more significant than that of pregabalin.

Key words: Pregabalin, chronic neuropathic pain, morphine, sciatic nerve ligation.
\end{abstract}

\section{INTRODUCTION}

$\mathrm{T}$ The development of newer classes of antiepileptic drugs has created several opportunities for the treatment of epilepsy as well as pain especially the neuropathic pain. These drugs modulate pain transmission by interacting with specific neurotransmitters and ion channels [1].

Pregabalin is a recent antiepileptic drug that shows efficacy in treatment of partial seizures with or without secondary generalization ${ }^{[2]}$, diabetic neuropathy\& Cancer pain with bone metastasis ${ }^{[3]}$, Post-operative pain ${ }^{[4]}$, Post-herpetic neuralgia ${ }^{[5]}$, Fibromyalgia and irritable bowel syndrome ${ }^{[6]}$.

Pregabalin appears to exert its effect through enhancement of gamma-aminobutyric acid (GABA) mediated transmission or react with ion-channels in neurons. Pregabalin binds to the $\alpha 2 \delta$ (alpha2delta) subunit of the voltagedependent calcium channel in the central nervous system. This reduces calcium influx into the nerve terminals ${ }^{[2]}$.

This study was aimed to assess and compare the effects of the antiepileptic drug pregabalin and the traditional analgesic morphine on acute pain in normal rats and on chronic neuropathic pain in rats subjected to sciatic nerve ligation.

\section{MATERIALS AND METHODS}

Drugs and chemicals: Pregabalin (Lyrica), capsules, $150 \mathrm{mg}$ \{Pfizer co., Egypt\}, Morphine (morphine sulfate), ampoules, $20 \mathrm{mg} / 1 \mathrm{ml}$ \{Misr co., Egypt $\}$, Thiopental (Sodium thipental), Vials: $500 \mathrm{mg}$ \{EIPICO, Egypt\}. All the above drugs were dissolved in distilled water just before administration. Morphine and thiopental were given by intraperitoneal injection while pregabalin was given orally.

Animals: A total number of 72 adult male albino rats weighing 200-250 gm were used in this study. They were maintained in cages with free access to food and water and kept on a 12-h light/dark schedule.

Experimental protocol; Rats in this work were divided into two main independent groups as follows:

The first group was conducted to study the effect of pregabalin and morphine on acute thermal nociception (30 rats):

Rats in this group were divided randomly into 5 equal subgroups (6 rats each): group1 (control group): Received distilled water, group 2 Received pregabalin $30 \mathrm{mg} / \mathrm{kg}$, group3 Received morphine $0.5 \mathrm{mg} / \mathrm{kg}$, group4 Received pregabalin $60 \mathrm{mg} / \mathrm{kg}$ 
and group 5 Received morphine $1 \mathrm{mg} / \mathrm{kg}$. For each group the reaction time was measured after 30, 60 and $90 \mathrm{~min}$. of drug administration.

The second group was conducted to study the effect of pregabalin and morphine on chronic neuropathic pain induced in rats by sciatic nerve ligation (42 rats):

Neuropathic pain was induced in experimental animals by unilateral ligation of the sciatic nerve in the thigh under general anesthesia with $40 \mathrm{mg} / \mathrm{kg}$ thiopental Barnes and Eltherington ${ }^{[7]}$. The right sciatic nerve is exposed and isolated at the mid thigh and one third to one half of the nerve is ligated tightly with 5-0 silk suture. Within few hours after the operation and for several months thereafter, the rats develop a guarding behavior of the ipsilateral hind paw and lick it. The cause of this behavior is development of hyperalgesia. The plantar surface of the foot became highly sensitive to nonnoxious and noxious stimuli and a sharp decrease in the reaction time measured by analgesia meter in response to thermal stimulation is noticed Seltzer et al., ${ }^{[8]}$.

Rats in this group were divided randomly into 7 equal subgroups (6 rats each): group1 (Sham operated): They were subjected to sham operation and administered distilled water orally. Group2 (control normal): received distilled water orally and not subjected to any surgical intervention. Group3 (Control postoperative): subjected to sciatic nerve ligation and left in standard environment for two weeks then received distilled water orally. Animals of group 4, 5,6,7 were also subjected to sciatic nerve ligation and left in standard environment for two weeks then received the tested drug as follows: group4 received pregabalin $30 \mathrm{mg} / \mathrm{kg}$, group5 received morphine $0.5 \mathrm{mg} / \mathrm{kg}$, group6 received pregabalin $60 \mathrm{mg} / \mathrm{kg}$ and group7 morphine $1 \mathrm{mg} / \mathrm{kg}$.

The above doses are equivalent to the human therapeutic doses according to Paget and Barnes table, ${ }^{[9]}$. In all groups the reaction times were measured 30, 60 and 90 minutes after drug administration.

\section{STATISTICAL ANALYSIS}

The obtained data were tabulated as means \pm standard errors. Comparison between different groups were made using one way analysis of variances (one-way ANOVA) followed by post-hoc (least significant difference LSD) test. The differences were considered to be significant when $\mathrm{p}<0.05$. Statistical Package of Social Sciences (SPSS) computer software (version 10) was used to carry out the statistical analysis Swinscow, ${ }^{[10]}$.

\section{RESULTS}

Effect of pregabalin (PGB) $(30 \mathrm{mg} / \mathrm{kg}$ oral $)$ and morphine $(0.5 \mathrm{mg} / \mathrm{kg}$ intraperitoneal $)$ on the reaction time in rats subjected to acute pain (table 1).

The results showed that the mean values of the reaction time in pregabalin treated group at 30,60 and 90 minutes were insignificantly different in relation to each other and in relation to the results of the control group.

The values of the reaction time in the morphine treated group were significantly higher than those of the control and pregabalin treated groups.

Table (1): $\quad$ Effect of pregabalin $(30 \mathrm{mg} / \mathrm{kg}$ oral) and morphine sulfate $(0.5 \mathrm{mg} / \mathrm{kg}$ intraperitoneal) on reaction time in rats subjected to acute pain

\begin{tabular}{lcccc}
\hline & $\begin{array}{c}\text { Group } \\
(\mathrm{N}=6)\end{array}$ & Control & Pregabalin treated & Morphine treated \\
Time & & $6.77 \pm 0.37$ & $7.39 \pm 0.23$ & $12.39 \pm 0.30$ \\
\hline $\begin{array}{l}\text { At 30 } \\
\text { minutes }\end{array}$ & $\mathrm{A}$ & $\mathrm{A}$ & $\mathrm{B}$ \\
\hline $\begin{array}{l}\text { At 60 } \\
\text { minutes }\end{array}$ & $6.98 \pm 0.47$ & $7.00 \pm 0.34$ & $12.00 \pm 0.32$ \\
\hline $\begin{array}{l}\text { At 90 } \\
\text { minutes }\end{array}$ & $\mathrm{A}$ & $\mathrm{A}$ & $\mathrm{B}$ \\
\hline
\end{tabular}

- $\quad$ All values are means of the reaction time in seconds \pm standard errors.

- Values with common subscript capital letters are insignificant with each other.

- $\quad \mathrm{N}=$ the number of animals in each group.

Effect of pregabalin (60 $\mathrm{mg} / \mathrm{kg}$ oral $)$ and morphine (1 $\mathrm{mg} / \mathrm{kg}$ intraperitoneal) on the reaction time in rats subjected to acute pain (table 2). 
Statistical analysis revealed that the results of pregabalin and control groups were insignificantly different in relation to each other

Table (2): $\quad$ Effect of pregabalin $(60 \mathrm{mg} / \mathrm{kg}$ oral $)$ and morphine $(1 \mathrm{mg} / \mathrm{kg}$ intraperitoneal) on the reaction time in rats subjected to acute pain.

\begin{tabular}{|c|c|c|c|}
\hline $\mathrm{F}_{\text {Time }}$ & Control & Pregabalin treated & Morphine treated \\
\hline $\begin{array}{l}\text { At } 30 \\
\text { minutes }\end{array}$ & $\begin{array}{c}6.77 \pm 0.37 \\
\mathrm{~A}\end{array}$ & $\begin{array}{c}7.06 \pm 0.44 \\
\mathrm{~A}\end{array}$ & $\begin{array}{c}12.77 \pm 0.25 \\
B\end{array}$ \\
\hline $\begin{array}{l}\text { At } 60 \\
\text { minutes }\end{array}$ & $\begin{array}{c}6.98 \pm 0.47 \\
\mathrm{~A}\end{array}$ & $\begin{array}{c}7.15 \pm 0.13 \\
\mathrm{~A} \\
\end{array}$ & $\begin{array}{c}13.01 \pm 0.43 \\
B \\
\end{array}$ \\
\hline $\begin{array}{l}\text { At } 90 \\
\text { minutes }\end{array}$ & $\begin{array}{c}7.12 \pm 0.46 \\
\mathrm{~A}\end{array}$ & $\begin{array}{c}7.00 \pm 0.18 \\
\mathrm{~A}\end{array}$ & $\begin{array}{c}12.49 \pm 0.41 \\
B\end{array}$ \\
\hline
\end{tabular}

- All values are means of the reaction time in seconds \pm standard errors.

- Values with common subscript capital letters are insignificant with each other

- $\mathrm{N}=$ the number of animals in each group.

Effect of pregabalin (30 $\mathrm{mg} / \mathrm{kg}$ oral) and morphine $(0.5 \mathrm{mg} / \mathrm{kg}$ intraperitoneal) on chronic neuropathic pain induced in rats by sciatic nerve ligation. (table $3 \& 4$ ).

The values of reaction time in the control and the sham operated groups were insignificantly different. and were significantly reduced in relation to the corresponding results of morphine treated group. different.

(1)

$\sqrt{2}$

$\frac{\text { Table (3): Reaction time changes in sham operated rats }}{\text { Group }}$

\begin{tabular}{|c|c|c|}
\hline $\begin{array}{rr}\begin{array}{r}\text { Group } \\
(\mathrm{N}=6)\end{array} \\
\end{array}$ & $\begin{array}{l}\text { Control } \\
\text { normal }\end{array}$ & Sham operated \\
\hline $\begin{array}{l}\text { At } 30 \\
\text { Minutes }\end{array}$ & $\begin{array}{c}6.77 \pm 0.37 \\
\mathrm{~A} \\
\end{array}$ & $\begin{array}{c}6.76 \pm 0.09 \\
\mathrm{~A}\end{array}$ \\
\hline $\begin{array}{l}\text { At } 60 \\
\text { Minutes }\end{array}$ & $\begin{array}{c}6.98 \pm 0.47 \\
\mathrm{~A}\end{array}$ & $\begin{array}{c}7.06 \pm 0.20 \\
\mathrm{~A}\end{array}$ \\
\hline $\begin{array}{l}\text { At } 90 \\
\text { Minutes }\end{array}$ & $\begin{array}{c}7.12 \pm 0.46 \\
\text { A }\end{array}$ & $\begin{array}{c}7.13 \pm 0.19 \\
\mathrm{~A}\end{array}$ \\
\hline
\end{tabular}

- All values are means of the reaction time in seconds \pm standard errors.

- Values with common subscript capital letters are insignificant with each other.

- $\quad \mathrm{N}=$ the number of animals in each group.

Table (4): Effect of pregabalin $(30 \mathrm{mg} / \mathrm{kg}$ oral) and morphine $(0.5 \mathrm{mg} / \mathrm{kg}$ intraperitoneal) on chronic neuropathic pain.

\begin{tabular}{lcccc}
\hline $\begin{array}{r}\text { Group } \\
(\mathbf{N}=6)\end{array}$ & $\begin{array}{c}\text { Control } \\
\text { normal }\end{array}$ & $\begin{array}{c}\text { Control } \\
\text { postoperative }\end{array}$ & Pregabalin treated & Morphine treated \\
Time & $6.77 \pm 0.37$ & $2.92 \pm 0.14$ & $3.33 \pm 0.23$ & $8.95 \pm 0.02$ \\
\hline $\begin{array}{l}\text { At 30 } \\
\text { minutes }\end{array}$ & $\mathrm{A}$ & $\mathrm{B}$ & $\mathrm{B}$ & $\mathrm{C}$ \\
\hline At 60 & $6.98 \pm 0.47$ & $3.01 \pm 0.17$ & $6.68 \pm 0.30$ & $9.03 \pm 0.15$ \\
minutes & $\mathrm{A}$ & $\mathrm{B}$ & $\mathrm{A}$ & $\mathrm{C}$ \\
\hline $\begin{array}{l}\text { At 90 } \\
\text { minutes }\end{array}$ & $7.12 \pm 0.46$ & $3.20 \pm 0.15$ & $6.58 \pm 0.24$ & $6.08 \pm 0.12$ \\
\hline
\end{tabular}


- All values are means of the reaction time in seconds \pm standard errors.

- Values without common subscript capital letters are significantly different in relation to each other.

- $\mathrm{N}=$ the number of animals in each group.

Effect of pregabalin $(60 \mathrm{mg} / \mathrm{kg}$ oral $)$ and morphine $(1 \mathrm{mg} / \mathrm{kg})$ on chronic neuropathic pain (table 5).

The values of the reaction time of pregabalin treated group were significantly increased as compared with the control postoperative group and were significantly less than those of the morphine group at 30,60 , and 90 minutes.

Table (5): Effect of pregabalin $(60 \mathrm{mg} / \mathrm{kg}$ oral) and morphine $(1 \mathrm{mg} / \mathrm{kg}$ intraperitoneal) on chronic neuropathic pain.

\begin{tabular}{lcccc}
\hline $\begin{array}{c}\text { Group } \\
(\mathbf{N}=6)\end{array}$ & $\begin{array}{c}\text { Control } \\
\text { normal }\end{array}$ & $\begin{array}{c}\text { Control } \\
\text { postoperative }\end{array}$ & Pregabalin treated & Morphine treated \\
\hline $\begin{array}{l}\text { At 30 } \\
\text { minutes }\end{array}$ & $6.77 \pm 0.37$ & $2.92 \pm 0.14$ & $10.23 \pm 0.06$ & $16.77 \pm 0.05$ \\
\hline $\begin{array}{l}\text { At 60 } \\
\text { minutes }\end{array}$ & $6.98 \pm 0.47$ & $3.01 \pm 0.17$ & $10.05 \pm 0.12$ & $13.98 \pm 0.19$ \\
\hline $\begin{array}{l}\text { At 90 } \\
\text { minutes }\end{array}$ & $7.12 \pm 0.46$ & $3.20 \pm 0.15$ & $7.03 \pm 0.07$ & $\mathrm{C}$ \\
\hline
\end{tabular}

- All values are means of the reaction time in seconds \pm standard errors.

- Values without common subscript capital letters are significantly different in relation to each other.

- $\mathrm{N}=$ the number of animals in each group.

\section{DISCUSSION}

The result of the present study revealed that neither 30 nor $60 \mathrm{mg} / \mathrm{kg}$ pregabalin produced any significant effects on the tolerability of rats to acute thermal nociception all over the experiment. On the other hand, pregabalin (30 and $60 \mathrm{mg} / \mathrm{kg}$ ) markedly reversed allodynia and hyperalgesia in rats subjected to sciatic nerve ligation. The effect of pregabalin $30 \mathrm{mg} / \mathrm{kg}$ was noticed after 60 minutes and persist for 90 minutes but the higher dose $(60 \mathrm{mg} / \mathrm{kg})$ produced analgesic effect all over the experiment.

Our finding also revealed that morphine produced a significant increase in the paw withdrawal latency in both normal and sciatic nerve ligated rats. The analgesic effect of morphine was more significant than that of pregabalin.

The results of the present study are in agreement with Meymandi and Keyhanfar [11] who stated that pregabalin as like as gabapentin did not hold antinociceptive effect in transient models of pain such as tail-flick and hot-plate test, and that the analgesic effects of pregabalin depend on presence of nerve lesion.

Pregabalin was shown to be effective in several models of neuropathic pain. Pregabalin effectively blocked the development and the maintenance of thermal hyperalgesia and/or mechanical allodynia caused by intrathecal injection of Substance P or $N$-methyl-D-aspartate (NMDA) Partridge et al. ${ }^{[12]}$. Moreover pregabalin suppressed tactile allodynia in rats subjected to ischemic nerve injury Wallin et al. [13] , reduced thermal and mechanical hypersensitivity in a murine chronic pain model (Seltzer model) based on partial ligation of the sciatic nerve Takeuchi et al. ${ }^{[14]}$, and suppressed hyperalgesia in rats induced by spinal nerve ligation Field et al. ${ }^{[15]}$.

Pregabalin administered into the spinal cord attenuates nociceptive behaviors in an acute arthritis model in rats and also reduces nociceptive behaviors during the tonic phase of the formalin test $\mathbf{L u}$ and Westlund, ${ }^{[16]}$, which is thought to reflect central sensitization Coderre et al. ${ }^{[17]}$. Similarly, pregabalin blocks the maintenance of carrageenan-induced sensitization of dorsal horns in the joint acute arthritis model Houghton et al. ${ }^{[18]}$.

Our findings are supported by the findings of field et al. ${ }^{[19]}$ who found that S-(+)-3isobutylgaba $(1-100 \mathrm{mg} / \mathrm{kg})$ and gabapentin $(10-$ $300 \mathrm{mg} / \mathrm{kg}$ ) dose-dependently inhibited the late 
phase of the nociceptive response in formalin test. The authors also found that the effect of both drugs was insensitive to naloxone $(0.1-10.0 \mathrm{mg}$ $/ \mathrm{kg}$, s.c.). On the other hand, the R-(-)-enantiomer of 3-isobutylgaba $(1-100 \mathrm{mg} \mathrm{kg})$ produced a modest inhibition of the late phase at the highest dose of $100 \mathrm{mg} / \mathrm{kg}$. However, none of the compounds showed any effect during the early phase of the response.

Our results are also in agreement with the results of Han et al. ${ }^{[20]}$ who demonstrated that pregabalin has marked anti-allodynic effect on tactile and cold allodynia using von Frey filament and acetone drop testing in rat models of sympathetically maintained and sympathetic independent neuropathic pain.

Inhibition of excitatory amino acid release from primary afferents by pregabalin binding at calcium channel $\alpha 2 \delta$ subunits could result in reduced availability of glutamate at the NMDA, AMPA and metabotropic receptors Field et al. ${ }^{[21]}$. It has previously been shown that gabapentin binds with high affinity to the $\alpha 2 \delta$ subunit of a voltage-dependent calcium channel Gee et al. ${ }^{[22]}$.

Some studies suggest that the physiological role of the $\alpha 2 \delta$ subunit is to increase the functional expression of calcium channel complexes Gurnett et al. ${ }^{[23]}$. The $\alpha 2 \delta$ subunit appears to be common to all voltage-dependent calcium channels Hofmann et al. ${ }^{[24]}$. Therefore, it is conceivable that the antihyperalgesic actions of gabapentin and (S)-(+)-3-isobutylgaba involve more than one type of calcium channel.

Recently it is demonstrated that pregabalin binds with high affinity to the $\alpha 2 \delta$ type 1 and 2 subunits of calcium channels Taylor, [25] and inhibits calcium influx through presynaptic voltage-gated calcium channels $\mathbf{L i},{ }^{[26]}$. The inhibition of calcium influx reduces potassiumevoked excitatory transmitter release, thereby decreasing postsynaptic excitability. Experimental studies have revealed that the binding of pregabalin to the $\alpha 2 \delta$ auxiliary subunits of the calcium channels is necessary for its analgesic effects Taylor, ${ }^{[25]}$. The antiallodynic effect of pregabalin was found to be correlated with the upregulation of $\alpha 2 \delta$ subunits of voltage-dependent calcium channels in the spinal cord and/or dorsal root ganglia Luo et al. ${ }^{[27]}$. Pregabalin impairs anterograde trafficking of the $\alpha 2 \delta-1$ subunit, resulting in its decrease in presynaptic terminals, which reduces neurotransmitter release and spinal sensitization in rats with unilateral lumbar spinal nerve ligation Bauer et al. ${ }^{[28]}$.
Pregabalin attenuates enhanced neuronal responses to peripheral somatic inputs following nerve injury but, in contradiction to our results, it shows analgesic efficacy in acute colorectal distension models of visceral pain Million et al. [29]. The analgesic actions of pregabalin in neuropathy are proposed to be state-dependent and rely on up-regulation of the $\alpha_{2} \delta-1$ subunit of voltage gated calcium channels Bauer et al. ${ }^{[28]}$. The anti neuropathic pain drug pregabalin is thought to have state-dependent effects in attenuating neuropathic, but not acute somatic pain. Differential brainstem processing of noxious somatic and visceral stimuli may underlie the unique lack of state-dependent actions of pregabalin in visceral pain models.

A clinical trial with irritable bowel syndrome patients suffering from rectal hypersensitivity showed that pregabalin increased the distension sensory thresholds to normal levels Houghton et al. ${ }^{[30]}$. This is supported by the recent work of Meymandi and Keyhanfar [2] who stated that pregabalin had five times the potency of gabapentin and $1 / 85^{\text {th }}$ the potency of morphine in animal models of visceral pain. Pregabalin reduces spinal and brainstem activity, and its analgesic actions are not dependent on pathology in visceral pain. A common effect of pregabalin in visceral and somatic pain states entails a reduction in central nociceptive hyperexcitability. This could also underlie the analgesic efficacy of pregabalin in other pain states that develop in lack of any clear peripheral insult, such as irritable bowel syndrome and fibromyalgia Sikandar and Dickenson ${ }^{[6]}$.

Our findings are also supported by the work of Eutamene et al. ${ }^{[31]}$ who studied the antinociceptive effect of pregabalin on delayed visceral hyperalgesia induced in rats by i.p. lipopolysaccharide administration. Lipopolysaccharide leads to a delayed lowering threshold of abdominal contractions in response to rectal distension in awake rats. Pregabalin, when administered $2 \mathrm{~h}$ before rectal distension had potent antihyperalgesic effects on rectal allodynia. Moreover the visceral antiallodynic effect of pregabalin is not mediated by an opiate or a GABAergic mechanism.

Our findings are also in agreement with the work of D'Mello and Dickenson ${ }^{[32]}$ who stated that pregabalin is a starting option in the treatment of many neuropathic pain conditions where the enhanced response of the spinal cord and brain, referred to as central sensitization, 
develops following sufficient peripheral afferent barrage into the central nervous system.

The use of pregabalin, in acute postoperative pain management, has been evaluated in some studies. In the first trial, a dose of $300 \mathrm{mg}$ pregabalin administered after dental operation was more effective in attenuating pain than placebo. It also had a longer duration of analgesia than ibuprofen Stahl, ${ }^{[33]}$

In 2007 Tippana et al. ${ }^{[34]}$ analyzed 22 randomized, controlled trials examining the analgesic efficacy, adverse effects, and clinical value of gabapentinoids (pregabalin and gabapentin) in postoperative pain. They concluded that gabapentinoids effectively reduce postoperative pain, opioid consumption, and opioid-related side effects after surgery. Moreover at 2008; Jokela et al. ${ }^{[35]}$ observed that preoperative administration of $300 \mathrm{mg}$ pregabalin, followed by the same dose after 12 hours in patients undergoing laparoscopic hysterectomy decreases oxycodone consumption.

In a more recent study, Buvanendran et al. ${ }^{[4]}$ investigated the effect of perioperative pregabalin in reducing chronic pain after total knee arthroplasty. They administered pregabalin $300 \mathrm{mg}$ before surgery and continued it for 14 days (50-150 mg twice daily). They observed that perioperative pregabalin administration reduces the incidence of chronic neuropathic pain after total knee arthroplasty, with less opioid consumption and better range of motion during the first 30 days of rehabilitation.

At variance with these observations, Paech et al. ${ }^{[36]}$ reported that a single preoperative dose of $100 \mathrm{mg}$ pregabalin was ineffective in reducing acute postoperative pain or improving recovery after minor surgery involving only the uterus. This could possibly be attributed to a single small dose $(100 \mathrm{mg})$ as against the recommended $150 \mathrm{mg} /$ day.

Our results are also in agreement with the recent clinical trials of_Schneider et al. ${ }^{[3]}$ who demonstrated that pregabalin is effective in neuropathic cancer pain with bone metastasis. The authors stated that, if bone metastases resulted in compression of neural tissue (neuropathic cancer pain), coanalgesics, such as pregabalin and gabapentin should be prescribed, titrated and controlled according to their benefit or side effects.

Pregabalin is a safe and effective analgesic for neuropathic pain that allows relatively fast dose adjustments and also provides anxiolytic action Gaertner and Voltz ${ }^{[37]}$.
Also our findings are consistent with the work of Mishra et al. ${ }^{[38]}$ who conducted a prospective randomized double-blind placebocontrolled study to compare the efficacy of amitriptyline, gabapentin, and pregabalin in neuropathic cancer pain. The author demonstrated that all the tested drugs were effective in treating neuropathic cancer pain. Moreover there was statistically and clinically significant morphine sparing effect of pregabalin as compared to other drugs.

Our results are also consistent with the recent study of Sarakatsianou et al. ${ }^{[39]}$ who demonstrated that administration of $600 \mathrm{mg}$ pregabalin per os, divided in two preoperative doses, significantly reduces postoperative pain as well as opioid consumption in patients undergoing laparoscopic cholecystectomy.

Many studies demonstrated that gabapentinoids are also effective for treatment of post herpetic neuralgia Gan et al. ${ }^{[5]}$.

The results of the present study are in contradiction to the work of Kim et al. ${ }^{[40]}$ who tested the effect of morphine, pregabalin, celecoxib and ketorolac on neuropathic pain induced in rats by removal of nucleus pulposus from the lumbar discs (L4/L5 and L5/L6). The authors demonstrated that morphine $(6.7 \mathrm{mg} / \mathrm{kg})$ resulted in effective pain relief. However, pregabalin $(20 \mathrm{mg} / \mathrm{kg})$, celecoxib $(50 \mathrm{mg} / \mathrm{kg})$ and ketorolac $(20 \mathrm{mg} / \mathrm{kg})$ did not have significant antihyperalgesic effects in disk injury animal model. This may be attributed to the difference in tested doses as we used higher dose in our study.

Our findings are also in contradiction to the findings of Meymandi and Keyhanfar [11] who studied the antinociceptive effect of intraperitoneal administration of pregabalin ( 1 to $400 \mathrm{mg} / \mathrm{kg}$ ) and tramadol (10 to $80 \mathrm{mg} / \mathrm{kg}$ ) or combination of them. The effects were measured after 30 and $60 \mathrm{~min}$ on hot-plate in terms of maximum possible effect in mice. The authors demonstrated that pregabalin revealed antinociceptive effect in acute model of pain and its effect was similar to the effect of tramadol. Also Jarogniew [41] studied the effect of pregabalin on hot plate test in mice. The author demonstrated that pregabalin produced antinociceptive effects in a dose dependent manner using the acute thermal pain model (hotplate test) in mice.

Conclusion: Pregabalin was not effective for treatment of acute thermal pain. Pregabalin was significantly effective in treatment of chronic 
neuropathic pain. Morphine was effective in treatment of both types of pain. The analgesic effect of morphine was more significant than that of pregabalin.

\section{REFERENCES}

1- Hepner S., Claxton R., (2013): Anti-Epileptic Drugs for Pain. J. Palliative Med. 16(7): 799800.

2- Meymandi M.S., and Keyhanfar F., (2013): Relative potency of pregabalin, gabapentin, and morphine in a mouse model of visceral pain. Canad. j., anaesth. 60(1):44-9.

3- Schneider G., Voltz R., and Gaertner J., (2012): Cancer Pain Management and Bone Metastases: An Update for the Clinician. Breast Care. 7(2):113-120.

4- Buvanendran A, Kroin JS, Valle CJD, Kari M, Moric M, Tuman KJ. (2010): Perioperative oral pregabalin reduces chronic pain after total knee arthroplasty: A prospective, randomized, controlled trial. Anesth Analg.110:199-207.

5- Gan E.Y., Tian E.A., and Tey H.L., (2013): Management of herpes zoster and postherpetic neuralgia. Am J Clin Dermatol. 14(2):77-85.

6- Sikandar S., and Dickenson A.H., (2011): Pregabalin modulation of spinal and brainstem visceral nociceptive processing. Pain.152 (10):2312-22.

7- Barnes C.D. and Etherington L.G. (1964): Drug dosage in laboratory animals, a hand book. University of California press and Los Anglos P: 41

8- Seltzer Z., Dubner R. and Shir Y. (1990): A novel behavioral model of neuropathic pain disorders produced in rats by partial sciatic nerve injury. Pain, 43: 205-18

9- Paget G.F. and Barnes J.M. (1964): Toxicity tests. In Evaluation of drug activities, pharmacometric. academic press London and New York. Vol.1: 135.

10- Swinscow T.D. (1994): Statistics at square one. Articles published in the Br. Med. J. Ninth edition Latimer Trend and company Ltd. Plymouth, p:100-160.

11- Meymandi M.S., and Keyhanfar F., (2012): Pregabalin antinociception and its interaction with tramadol in acute model of pain. Pharmacol Rep. 64(3):576-85.

12- Partridge B.J., Chaplan S.R., and Sakamoto E., (1998): characterization of the effect of gabapenten and 3-isobutyl-GABA on substance $\mathrm{P}$ induced thermal hyperalgesia. Anesthesiology, 88:196-205.

13- Wallin J., Cui J, Yakhnitsa V., and Schechtmann G., (2002): Gabapentin and pregabalin suppress tactile allodynia and potentiate spinal cord stimulation in a model of neuropathy. European Journal of PaiN 6(4): 261-272.
14- Takeuchi Y., Takasu K., Ono H., Tanabe M. (2007): Pregabalin, S-(+)-3-isobutylgaba, activates the descending noradrenergic system to alleviate neuropathic pain in the mouse partial sciatic nerve ligation model. Neuropharmacology. 53:842-853.

15- Field M.J., McCleary S., Hughes J., Singh L., (1999): Gabapentin and pregabalin, but not morphine and amitriptyline, block both static and dynamic components of mechanical allodynia induced by streptozocin in the rat. Pain. 80:391-398.

16- Lu Y., and Westlund K.N., (1999): Gabapentin attenuates nociceptive behaviors in an acute arthritis model in rats. J Pharmacol Exp Ther 290:214-219.

17- Coderre T.J., Vacarino A.L., and Melzack R., (1990): Central nervous system plasticity in the tonic pain response to subcutaneous formalin injection. Brain Res 535:155-158.

18- Houghton A.K., Lu Y., and Westlund K.N., (1998): S-(+)-3-Isobutylgaba and its stereoisomer reduces the amount of inflammation and hyperalgesia in an acute arthritis model in the rat. J Pharmacol Exp Ther 285:533-538.

19- Field M.J., Li Z., Schwarz J.B., (2007): Ca2+ channel alpha2-delta ligands for the treatment of neuropathic pain. J Med Chem.;50:25692575.

20- Han D.W., Kweon T.D., Lee J.S., and Lee Y., (2007): Antiallodynic Effect of Pregabalin in Rat Models of Sympathetically Maintained and Sympathetic Independent Neuropathic Pain. Yonsei Med J. 48(1): 41-47.

21- Field M.J., Holloman E.F., McClearly S., (1997): evaluation of gabapentin and 3 (+)isobutyl-GABA in rat models of post operative pain.282:1242-1246.

22- Gee NS, Brown JP, Dissanayake VUK, Offord J, Thurlow R, and Woodruff GN (1996): The novel anticonvulsant drug, gabapentin (Neurontin), binds to the $\alpha_{2} \delta$ subunit of a calcium channel. J Biol Chem 271:5768-5776.

23- Gurnett CA, Dewaard M, and Campbell KP (1996): Dual function of the voltage dependent $\mathrm{Ca}^{2+}$ channel $\alpha_{2} \delta$ subunit in current stimulation and subunit interaction. Neuron 16:431-440.

24- Hofmann, F., Biel, M. and Flockerzi, V. (1994): Molecular basis for $\mathrm{Ca}^{2+}$ channel diversity. Annu. Rev. Neurosci., 17, 399-418.

25- Taylor C.P., (2009): Mechanisms of analgesia by gabapentin and pregabalin--calcium channel alpha2-delta [Cavalpha2-delta] ligands. Pain.142(1-2):13-6.

26- Li C.Y., Song Y.H., Higuera E.S., and Luo Z.D., (2004): Spinal dorsal horn calcium channel alpha2delta-1 subunit upregulation 
contributes to peripheral nerve injury-induced tactile allodynia. J. Neurosci. 24:8494-8499.

27- Luo Z.D., Calcutt N.A., Higuera E.S., Valder C.R., Song Y.H., Svensson C.I., Myers R.R. (2002): Injury type-specific calcium channel alpha 2 delta- 1 subunit up-regulation in rat neuropathic pain models correlates with antiallodynic effects of gabapentin. J Pharmacol Exp Ther. 303:1199-1205.

28- Bauer C.S., Nieto-Rostro M., Rahman W., Tran-Van-Minh A., Ferron L., Douglas L., (2009): The increased trafficking of the calcium channel subunit alpha2delta-1 to presynaptic terminals in neuropathic pain is inhibited by the alpha2delta ligand pregabalin. J Neurosci.29:4076-88.

29- Million M., Wang L., Adelson D.W., Roman F,. Diop L., Tache Y., (2007): Pregabalin decreases visceral pain and prevents spinal neuronal activation in rats. Gut. 56:1482-4.

30- Houghton L.A., Fell C., Whorwell P.J., Jones I., Sudworth D.P., Gale J.D. (2007): Effect of a second-generation alpha2delta ligand (pregabalin) on visceral sensation in hypersensitive patients with irritable bowel syndrome. Gut. 56:1218-1225.

31- Eutamene H, Coelho AM, Theodorou V, Toulouse M, Chovet M, Doherty A et al. (2000): Antinociceptive effect of pregabalin in septic shock-induced rectal hypersensitivity in rats. J Pharmacol Exp Ther295: 162-167.

32- D'Mello R., and Dickenson A.H., (2008): Spinal cord mechanisms of pain. $\mathrm{Br} J$ Anaesth. 101:8-16.

33- Stahl S.M., (2004): Mechanism of action of alpha2delta ligands voltage sensitive calcium channel (VSCC) modulators. J Clin Psychiatry. 65:1033-1034.

34- Tiippana EM, Hamunen K, Kontinen VK, Kalso E. (2007): Do surgical patients benefit from perioperative gabapentin/pregabalin? A systematic review of efficacy and safety. Anesth Analg. 104:1545-56.

35- Jokela R, Ahonen J, Tallgren M, Haanpää M, Korttila K. (2008): A randomized controlled trial of perioperative administration of pregabalin for pain after laparoscopic hysterectomy. Pain.;134:106-12.

36- Paech MJ, Goy R, Chua S, Scott K, Christmas T, Doherty DA. (2007): A randomized, placebo-controlled trial of preoperative oral pregabalin for postoperative pain relief after minor gynecological surgery. Anesth Analg. 105:1449-53.

37- Gaertner J and Voltz J. (2010): Breakthrough pain. J Palliat Med.13(3):345.

38- Mishra S., Bhatnagar S., Goyal G.N., Rana S.P., and Upadhya S.P., (2012): A comparative efficacy of amitriptyline, gabapentin, and pregabalin in neuropathic cancer pain: a prospective randomized doubleblind placebo-controlled study. Am J Hosp Palliat Care. 29(3):177-82.

39- Sarakatsianou C., Theodorou E., Georgopoulou S., Stamatiou G., and Tzovaras G. (2013): Effect of pre-emptive pregabalin on pain intensity and postoperative morphine consumption after laparoscopic cholecystectomy. Surg Endosc. 27(7):250411.

40- Kim J, Kroin J.S., Li X., An H.S., Buvanendran A., and Yan D., (2011): The rat intervertebral disk degeneration pain model: relationships between biological and structural alterations and pain. Arthritis Res Ther. 13(5): R165.

41- Jarogniew J.L (2011): Dose-response relationship analysis of pregabalin doses and their antinociceptive effects in hot-plate test in mice.62(5):1734-1140. 